\title{
Tandem Mass Spectrometric Analysis of a Complex Triterpene Saponin Mixture of Chenopodium quinoa
}

\author{
Tobias Madl, Heinz Sterk, and Martin Mittelbach \\ Department of Organic and Bioorganic Chemistry, Institute of Chemistry, Karl Franzens University, Graz, \\ Austria
}

\author{
Gerald N. Rechberger \\ Institute of Molecular Biosciences, Karl Franzens University, Graz, Austria
}

\begin{abstract}
A nano-HPLC electrospray ionization multi-stage tandem mass spectrometry (nLC-ESI-MS/ MS) approach was applied to a complex crude triterpene saponin extract of Chenopodium quinoa seed coats. In ESI-MS/MS spectra of triterpene saponins, characteristic fragmentation reactions are observed and allow the determination of aglycones, saccharide sequences, compositions, and branching. Fragmentation of aglycones provided further structural information. The chemical complexity of the mixture was resolved by a complete profiling. Eighty-seven triterpene saponins comprising 19 reported and 68 novel components were identified and studied by MS. In addition to four reported, five novel triterpene aglycones were detected and characterized according to their fragmentation reactions in ESI-MS/MS and electron ionization mass spectrometry (EI-MS). As a novelty fragmentation pathways were proposed and analyzed based upon quantum chemical calculations using a hybrid HartreeFock density functional method. Accuracy of the assignment procedure was proven by isolation and structure determination of a novel compound. As the relative distribution and composition of saponins varies between different cultivars and soils, the presented strategy allows a rapid and complete analysis of Chenopodium quinoa saponin distribution and composition, and is particularly suitable for quality control and screening of extracts designated for pharmaceutical, agricultural, and industrial applications. (J Am Soc Mass Spectrom 2006, 17, 795-806) (C) 2006 American Society for Mass Spectrometry
\end{abstract}

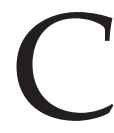

henopodium quinoa belongs to the plant family Chenopodiaceae and is widespread in South America [1]. The main field of usage is in nutrition, for which all parts of the plant are utilized. The seeds are outstanding because of their high protein quality and content [2,3]. However, they comprise triterpene saponins, which require special treatment before usage for nutritional purposes. Saponins are widespread in nature and represent a family of biochemically and pharmaceutically highly interesting compounds. Investigations on the biological and pharmacological activities of $C$. quinoa saponins gave toxicity to shrimps, inhibition of fungus growth, effects against viral diseases, cholesterol lowering effects, and an enhancing of mucosal drug absorption [4-7]. Although the above properties are adverse for nutrition, saponin extracts of $C$. quinoa are used in agriculture for treatment, control, and prevention of fungal and viral diseases [4]. In pharmaceutical compositions they act as

Published online April 17, 2006

Address reprint requests to Tobias Madl MS, Department of Organic and Bioorganic Chemistry, Institute of Chemistry, Karl Franzens University Graz, 8010 Graz, Austria. E-mail: tobias.madl@stud.uni-graz.at immunological and absorption adjuvants to enhance immune responses and mucosal absorption to a substance coadministered therewith [8]. These applications require quality control of the saponin extract as the relative distribution and composition of saponins varies between different cultivars and soils.

Saponins from C. quinoa were previously studied. Overall, four different aglycones, four monodesmosidic, and twenty-two bidesmosidic triterpene saponins are reported. The corresponding aglycones are oleanolic acid (OA), hederagenin (Hed), phytolaccagenic acid $(\mathrm{PA})$, and serjanic acid (SA), all of them deriving from $\beta$-amyrin (Scheme 1). Sugars can be linked to the aglycone at the C-3 and C-28. Among the major saccharides glucose (Glc), galactose (Gal), and arabinose (Ara), glucuronic acid (GlcA) and xylose (Xyl) were found to be less common [9-16].

The recent developments in the field of mass spectrometry-related hardware, especially electrospray ionization multi-stage tandem mass spectrometry (ESI$\mathrm{MS}^{\mathrm{n}}$ ) and nano-HPLC (nLC), opened up the door to natural product chemistry. The coupling of ESI-MS ${ }^{\text {n }}$ with nano-HPLC ( $\mathrm{nLC}$ ) allows studying saponin molecular species, aglycones, the saccharide sequence, mod- 

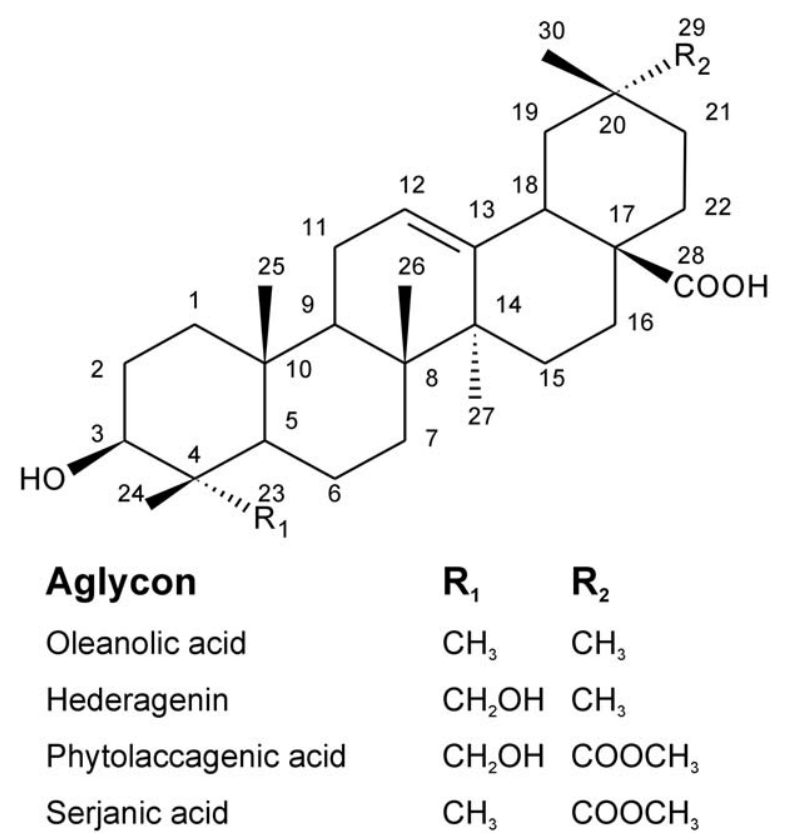

Scheme 1. Aglycones of reported C. quinoa triterpene saponins.

ification, branching [17-30], and deals with relative low amounts of sample, respectively. Due to the short analysis time (LC)-MS ${ }^{\mathrm{n}}$ analysis was recommended prior the common way of natural product identification [20]. However, previous studies mainly focused on the analysis of known saponins rather than identification and complete profiling of novel compounds.

Here, we present the application of an nLC-MS/MS approach to the complex crude saponin extract of $C$. quinoa to resolve the chemical complexity by a complete profiling. Nineteen reported and more than 70 previously unknown components were identified and assigned according to their aglycones, saccharide sequences, compositions, and branching. A total number of nine different aglycones comprising the four aglycones mentioned above and five new aglycones were detected. To the best of our knowledge this is one of the most comprehensive assignments of saponins ever attempted. As an additional novelty fragmentation pathways were proposed based upon quantum chemical calculations using a hybrid Hartree-Fock density functional method. The presented strategy allows a rapid and complete analysis of saponin distribution and composition in C. quinoa and is particularly suitable for screening extracts designated for pharmaceutical, agricultural and industrial applications.

\section{Experimental}

\section{Plant Material}

C. quinoa seed coats were collected from C. quinoa plants cultivated in lower Austria (Leopold Posch, Obergrafendorf, Lower Austria, Austria).

\section{Extraction and Purification \\ of Chemical Constituents}

Seed hulls, $20.0 \mathrm{~g}$, were treated with $300 \mathrm{ml}$ water/ ethanol (1:1), stirred for $3.5 \mathrm{~h}$ at $45{ }^{\circ} \mathrm{C}$ and centrifuged. The water/ethanol phase was decanted, the seed hulls were washed with $100 \mathrm{ml}$ water/ethanol, centrifuged, decanted, and ethanol was removed under reduced pressure; $100 \mathrm{ml}$ of distilled water were added to the water phase. Extraction of the saponins was performed with $100 \mathrm{ml}$ 1-butanol each. The 1-butanol layers were merged, centrifuged, and lyophilized [yellowish product; yield: $9.2 \%(\mathrm{wt} / \mathrm{wt})]$. The saponins were further purified using silica gel column chromatography [150 g, chloroform/methanol/water (65/35/10, vol/vol/vol) used as eluent]. Five g crude saponin mixture obtained from several extractions under identical conditions was applied to the column. Fractions of $20 \mathrm{ml}$ were collected and monitored by TLC [precoated plates, silica gel 60 $\mathrm{F}_{254}, 0.2 \mathrm{~mm}$, Merck, Darmstadt, Germany; chloroform/ methanol/water $(65 / 35 / 10, \mathrm{vol} / \mathrm{vol} / \mathrm{vol})$ as eluent] as well as by LC-MS. Visualization of the saponins was performed by immersion of the TLC plate into methanol/glacial acetic acid/sulphuric acid/anisaldehyde (170/20/10/1, vol/vol/vol/vol) followed by heating the TLC plate $\left(100{ }^{\circ} \mathrm{C}, 10 \mathrm{~min}\right)$. Fractions containing a novel saponin were merged and the solvent was removed (yellowish residue; yield $1.30 \mathrm{~g}$ ). This purified residue was dissolved in chloroform/methanol/water $(65 / 35 / 10, \mathrm{vol} / \mathrm{vol} / \mathrm{vol})$, applied to the column and rechromatographed as described above. Fractions containing the compound were merged and the solvent was removed (colorless residue; yield: $180 \mathrm{mg}$ ). Further purification of the saponins was done with semipreparative HPLC on a Hewlett Packard (HP) 1100 Series HPLC system equipped with a variable wavelength detector set at $220 \mathrm{~nm}$ (HP, Palo Alto, CA). The isocratic separation $(83 \%$ water, $17 \%$ acetonitrile at 5 $\mathrm{ml} / \mathrm{min}$ ) was carried out on a $\mathrm{C}_{18}$ reversed-phase (RP) column (Lichrospher $100 \mathrm{RP}-18,250 \times 10 \mathrm{~mm}, 10 \mu \mathrm{m}$, Merck, Germany). The saponin of interest was eluted as a single peak, the fractions were collected manually, combined, concentrated, and lyophilized (white amorphous powder; yield: $61 \mathrm{mg}$ ).

\section{Acidic Hydrolysis}

Twenty mg of the crude saponin extract were placed in a $20 \mathrm{ml}$ headspace vial and diluted in $15 \mathrm{ml} \mathrm{HCl}(1 \mathrm{M})$. The headspace vial was sealed and placed in an oven at $90^{\circ} \mathrm{C}$ for $2 \mathrm{~h}$, cooled to room temperature, and its seal broken. Compounds were extracted with ethyl acetate, $500 \mathrm{mg}$ calcium carbonate was added, and ethyl acetate was removed. To obtain monosaccharides, the aqueous layer was evaporated to dryness. For GC/MS measurements $200 \mu \mathrm{l}$ MSTFA were added to each of the residues and incubated at $50^{\circ} \mathrm{C}$ for $1 \mathrm{~h}$. 


\section{Solid Phase Extraction}

The octadecyl silica stationary phase [Isolute $\mathrm{C}_{18}, 1 \mathrm{~g} / 6$ $\mathrm{ml}$, ICT, Basel, Switzerland] was conditioned with water. Twenty $\mathrm{mg}$ of the samples were diluted in $5 \mathrm{ml}$ of water, applied onto the column, and eluted with methanol.

\section{Gas Chromatography Mass Spectrometry}

Gas chromatography electron ionization mass spectrometry (GC/MS) was performed on a HP 6890 GC system including a HP 5973 mass spectrometer equipped with an EI source. GC parameters were as follows: initial temperature was set at $50{ }^{\circ} \mathrm{C}(3 \mathrm{~min})$, temperature ramp was $15{ }^{\circ} \mathrm{C} / \mathrm{min}$ to $310^{\circ} \mathrm{C}(25 \mathrm{~min}$ hold), inlet was split (1:40, $40 \mathrm{ml} / \mathrm{min})$. The separations were carried out using a HP 5MS capillary column (30 $\mathrm{m} \times 250 \mu \mathrm{m}, 1 \mu \mathrm{m}$, HP, Palo Alto, CA) with helium as carrier gas $(1 \mathrm{ml} / \mathrm{min}, 54 \mathrm{kPa})$. Spectra were obtained over $\mathrm{m} / \mathrm{z} 20-800$. Sample preparation was done by diluting $1 \mathrm{mg}$ of the trimethylsilylated sapogenin mixture in $1 \mathrm{ml}$ HPLC grade methanol. Injection volume was $1 \mu$ l. System control and data evaluation was done on the HP Enhanced ChemStation software package, G1701BA Rev. B.01.00 (HP, Palo Alto, CA).

\section{Liquid Chromatography Mass Spectrometry}

HPLC separations were done on a HP 1100 Series HPLC system including a variable wavelength detector set at $220 \mathrm{~nm}$ (HP, Palo Alto, CA). The separations were carried out on a $\mathrm{C}_{18} \mathrm{RP}$ column (Zorbax Eclipse XDB, $150 \times 4.6 \mathrm{~mm}, 5 \mu \mathrm{m}, \mathrm{HP}$, Palo Alto, CA) at $20^{\circ} \mathrm{C}$. The mobile phase was a nonlinear gradient $(90 \%$ to $70 \%$ in $30 \mathrm{~min}, 70 \%$ to $50 \%$ in $10 \mathrm{~min}$ ) from $90 \%$ water/ acetonitrile $(9: 1, \mathrm{vol} / \mathrm{vol}), 10 \%$ acetonitrile to $50 \%$ water/acetonitrile, and $50 \%$ acetonitrile. $0.1 \%(\mathrm{vol} / \mathrm{vol})$ formic acid was added to the mobile phase. Flow rate was $0.7 \mathrm{ml} / \mathrm{min}$. System control and data evaluation was done on the HP LC/MSD Chemstation software package, Rev. A.06.05 (HP). ESI-MS was performed on a HP LC/MSD single quadrupole MS (SQMS; HP, Palo Alto, CA). The ESI-MS conditions were as follows: nitrogen was used as nebulizer/drying gas $(13 \mathrm{l} / \mathrm{min}$, $\left.350^{\circ} \mathrm{C}\right)$, capillary voltage was set at $+4 \mathrm{kV}$ and fragmentor voltage was set at $200 \mathrm{~V}$. Spectra were obtained over $\mathrm{m} / \mathrm{z}$ 300-1500. System control and data evaluation was done on the HP LC/MSD Chemstation software package, Rev. A.06.03 (HP). nLC was performed using an Agilent 1100 Series nanoflow LC system with a $40 \mu \mathrm{l}$ sample loop. Sample volumes of $20 \mu \mathrm{l}$ were injected and concentrated on a trapping column (Zorbax SB- $\mathrm{C}_{18}, 5$ $\mathrm{mm} \times 300 \mu \mathrm{m}, 5 \mu \mathrm{m}$ ) with water containing $0.1 \%$ formic acid at $20 \mu \mathrm{l} / \mathrm{min}$. After $5 \mathrm{~min}$ the samples were loaded onto the analytical column (Zorbax 300 SB-C ${ }_{18}$, $150 \mathrm{~mm} \times 75 \mu \mathrm{m}, 3.5 \mu \mathrm{m}$ ), which had been equilibrated with $97 \%$ A (100\% water, $0.1 \%$ formic acid) and 3\% B
( $95 \%$ acetonitrile, $5 \%$ water, $0.1 \%$ formic acid). Saponins were eluted using the following gradient: $0-60 \mathrm{~min}$, $3-60 \%$ B; $60-65 \mathrm{~min}, 60-95 \% \mathrm{~B} ; 65-65 \mathrm{~min}, 95 \% \mathrm{~B}$, at flow rates of $250 \mathrm{nl} / \mathrm{min}$. The $\mathrm{nLC}$ system was coupled online to an Agilent LC/MSD XCTPlus ion trap mass spectrometer (Agilent, Palo Alto, CA), equipped with a nano-electrospray ionization source (nLC-ITMS). For nano-electrospray, coated fused-silica PicoTips (New Objective, Woburn, MA) were used. The capillary voltage was set to 1500 and $1750 \mathrm{~V}$. Mass spectral data were acquired over $\mathrm{m} / \mathrm{z} 350-1800$. Nitrogen was used as nebulizer gas $\left(6 \mathrm{l} / \mathrm{min}, 260^{\circ} \mathrm{C}\right)$.

\section{Computational Details}

As calculations on the entire saponins are too time consuming, density-functional calculations were performed on model compounds. Three-ring substructures of the aglycones gaining monosaccharides retained structural relevant information and allowed calculations in an acceptable amount of time (see Supplementary Material section which can be found in the electronic version of this article.) Structures were drawn, model-built and pre-optimized using the semi-empirical PM3 method implemented in HyperChem 7.1 [31]. Spin pairing was computed according to RHF. In the SCF controls the accelerate convergence was selected (convergence limit: 0.01). Optimization was performed using the Polak-Ribiere algorithm (conjugate gradient; termination condition: RMS gradient of 0.01). These geometries were used as starting geometries for the Gaussian 03 suite of programs [32], using Becke's three-parameter hybrid Hartree-Fock density functional method [33] in combination with the Lee-Yang-Parr correlation functional (B3LYP) [34] and the 6-31g(d) basis set. All structures arising from the investigated fragmentation reactions were optimized and their energies taken for the discussion. Most of the structures were characterized by frequency calculations as true minima.

\section{$N M R$}

NMR experiments were done on a Bruker DRX-500 spectrometer (Bruker, Rheinstetten, Germany) equipped with an $\mathrm{HX}$ inverse probe $\left({ }^{1} \mathrm{H}: 500 \mathrm{MHz} ;{ }^{13} \mathrm{C}: 125 \mathrm{MHz}\right.$; solvent: pyridine- $\left.d_{5}\right)$. ${ }^{1} \mathrm{H}$ NMR, ${ }^{13} \mathrm{C}$ NMR, ${ }^{1} \mathrm{H}-{ }^{1} \mathrm{H}$ correlation (COSY), 1D and 2D total correlation (TOCSY), distortionless enhancement by polarization transfer (DEPT), heteronuclear multiple quantum/bond coherence/correlation (HMQC/HMBC), nuclear Overhauser effect (NOESY), and selective TOCSY, selective NOESY, and selective TOCSY-NOESY spectra were recorded using standard Bruker pulse sequences. System control and data evaluation was done with the XWINNMR software package, version 2.6 (Bruker, Rheinstetten, Germany). 


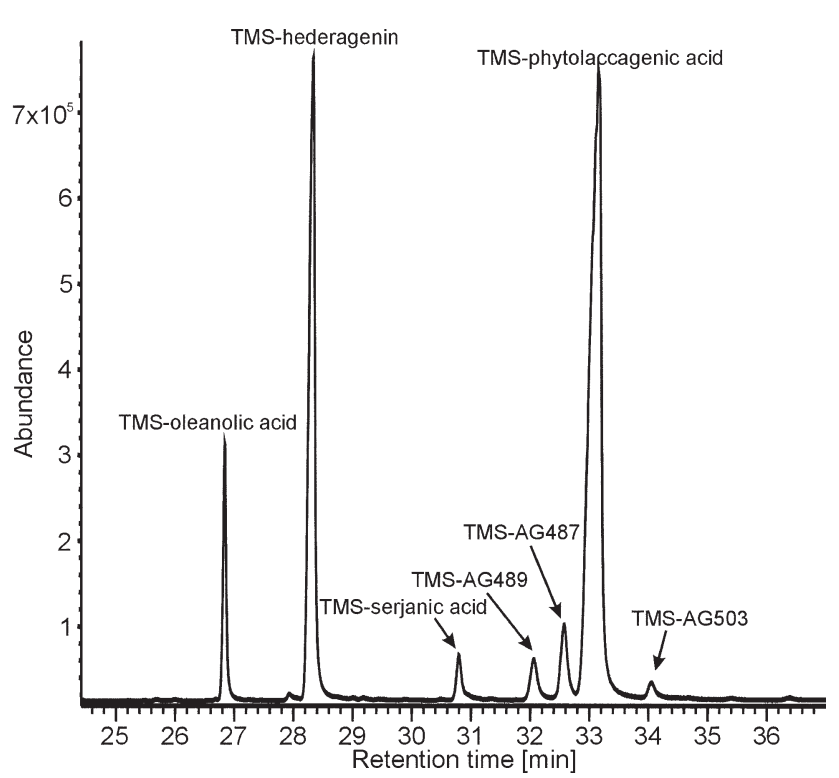

Figure 1. GC/MS chromatogram of trimethylsilylated C. quinoa triterpene aglycones.

\section{Results and Discussion}

\section{Assignment Strategy}

In natural product chemistry, one usually deals with highly complex and varying mixtures of compounds. As a consequence, for various applications, quality control of the extract regarding saponin composition and relative distribution is essential. In addition to this, metabolic profiling of extracts of partially or totally unknown composition gives an overview on the mixture, allows identification of the main compounds and can be followed up by directed compound isolation and structure determination. Within this study, the following assignment strategy was used to deal with a relative high number of compounds. First, the aglycones were identified by GC/MS analysis of hydrolysis products. Even though in the case of $C$. quinoa the main compounds were published in previous works, three new aglycones were detected (Figure 1). In the second step successive LC-MS and nLC-MS/MS analysis were used to identify the aglycone, to distinguish between saccharides, and to determine the oligosaccharide sequence and branching.

\section{Assignment and Fragmentation of Reported Saponins}

Separation of C. quinoa saponins using a modified water/acetonitrile based gradient described before [35] was adequately and allows identification a multitude of different saponins in an acceptable amount of time (Figure 2). Saponins were detected as $[\mathrm{M}+\mathrm{Na}]^{+}$ (SQMS) or $[\mathrm{M}+\mathrm{H}]^{+}$(ITMS). All compounds comprising a sugar acid (Table 1; E, F, K, R, S) gave an additional signal at $[\mathrm{M}+2 \mathrm{Na}-\mathrm{H}]^{+}$, which is probably arising from the sodium salt and can be used as an auxiliary restraint in the assignment procedure. Assignment was started by matching the detected molecular ions to those of the previously reported compounds (Table 1). The $m / z 1165$ (A), $m / z 943$ (F), $m / z 1119$ (G), $m / z 767(\mathbf{J})$, and $m / z 795(\mathbf{K})$ corresponding to the $[\mathrm{M}+$ $\mathrm{H}^{+}$ion were detected once, whereas several ions corresponding to the other compounds were found (Tables 1 and 2). These ambiguities can be resolved by tandem MS in the case that the compounds have different aglycones and/or variable sugar sequences and/or branching. However, different monosaccharide epimers cannot be distinguished. As a consequence, a differentiation of pentoses (Pent), hexose (Hex) and hexose acids (HexA) is given here. Product ion series of the oligosaccharide moiety and aglycones confirmed the latter compounds and allowed assignment of $\mathrm{C}, \mathrm{E}$, $\mathbf{H}, \mathbf{L}$, and $\mathbf{M}$. Although $[\mathrm{M}+\mathrm{H}]^{+}$ions of the major saponins $\mathbf{B}, \mathbf{D}$, and I were detected, they can be assigned as shown in Figure 2 because they represent the highest quantity within the chromatogram. No unique assignment was possible for Compounds $\mathbf{N}, \mathbf{O}$, $\mathbf{P}, \mathbf{Q}, \mathbf{R}$, and $\mathbf{S}$. For all of those, both the oligosaccharide sequence and the aglycones were identical. The most probable reasons for this observation are variations between different sugar epimers as found for Compounds $\mathbf{R}$ and $\mathbf{S}$, where $\mathrm{Xyl}$ is replaced by Ara. This is emphasized by GC/MS results, which restricted the saccharide pool to Xyl, Ara, Glc, Gal, GlcA, and Glc for the C-3 and C-28 saccharide, respectively. For N, O, P, and $\mathbf{Q}$ up to four compounds agreeing in sugar sequences and aglycones were detected (Table 2). Saponins were found to be clustered in characteristic retention time windows according to their aglycone (Figure 3). For C. quinoa saponins modifications within the saccharide moiety have a small effect on retention time whereas an exchange of the aglycone shifts reten-

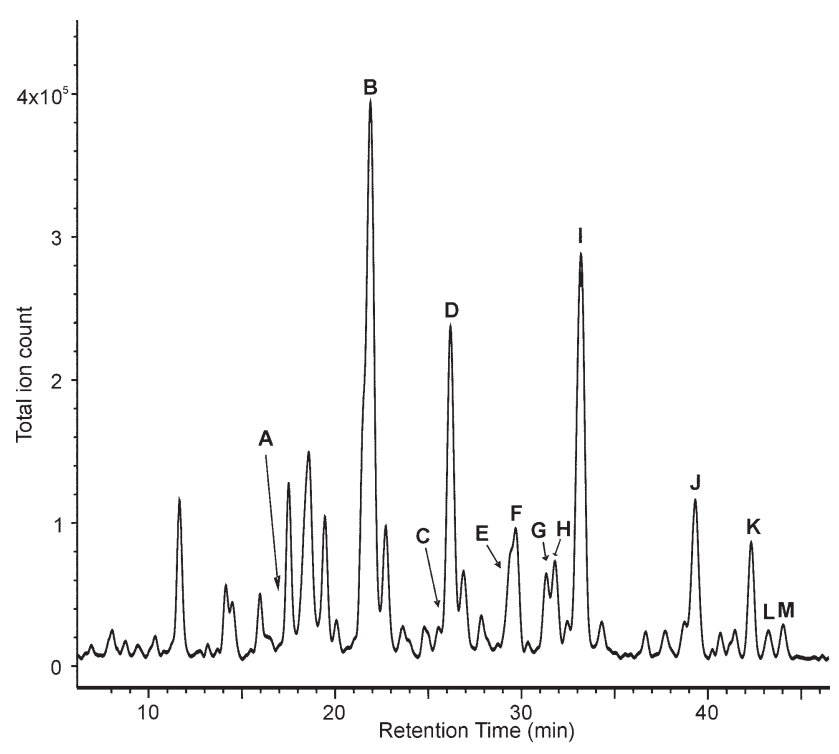

Figure 2. LC/MS chromatogram of C. quinoa triterpene saponins. A to $\mathbf{M}$ refer to the assigned literature-reported compounds. 
Table 1. Assignment of reported C. quinoa triterpene saponins

\begin{tabular}{|c|c|c|c|c|c|c|c|c|c|c|}
\hline & & & & & & $/ z^{d}$ & & & & \\
\hline & $t_{R}{ }^{a}$ & aglycone $^{\mathrm{b}}$ & 3-O saccharide $^{c}$ & {$[\mathrm{M}+\mathrm{Na}]^{+}$} & {$[\mathrm{M}+\mathrm{H}]^{+}$} & 1 & II & III & IV & References \\
\hline A & 17.0 & PA & $\mathrm{Glc}\left(1^{\prime \prime \prime} \rightarrow 4^{\prime \prime}\right) \mathrm{Glc}\left(1^{\prime \prime} \rightarrow 4^{\prime}\right) \mathrm{Glc}-$ & 1187 & 1165 & 1003 & 841 & 679 & 517 & {$[42]$} \\
\hline B & 21.9 & PA & Glc $\left(1^{\prime \prime} \rightarrow 3^{\prime}\right)$ Ara- & 995 & 973 & 811 & 649 & 517 & & {$[7,43-46]$} \\
\hline $\mathrm{C}$ & 25.5 & Hed & $\mathrm{Glc}\left(1^{\prime \prime \prime} \rightarrow 4^{\prime \prime}\right) \mathrm{Glc}\left(1^{\prime \prime} \rightarrow 4^{\prime}\right) \mathrm{Glc}-$ & 1143 & 1121 & 959 & 797 & 635 & 473 & {$[42]$} \\
\hline $\mathrm{D}$ & 25.1 & PA & Ara- & 833 & 811 & 649 & 517 & & & {$[7,45,46]$} \\
\hline$E$ & 29.2 & Hed & GlcA- & 833 & 811 & 649 & 473 & & & [46] \\
\hline $\mathrm{F}$ & 29.6 & Hed & $\mathrm{Xyl}\left(1^{\prime \prime} \rightarrow 3^{\prime}\right) \mathrm{GlcA}-$ & $965 / 987$ & 943 & 781 & 649 & 473 & & {$[46]$} \\
\hline G & 31.2 & SA & Glc $\left(1^{\prime \prime \prime} \rightarrow 2^{\prime \prime}\right) \mathrm{Glc}\left(1^{\prime \prime} 3^{\prime}\right)$ Ara- & 1141 & 1119 & 957 & 795 & 633 & 501 & {$[44,45]$} \\
\hline $\mathrm{H}$ & 31.8 & SA & $\mathrm{GIc}\left(1^{\prime \prime} \rightarrow 2^{\prime}\right)$ Ara- & 979 & 957 & 795 & 633 & 501 & & {$[44,45]$} \\
\hline I & 33.1 & Hed & GIc $\left(1^{\prime \prime} \rightarrow 3^{\prime}\right)$ Ara- & 951 & 929 & 767 & 605 & 473 & & {$[7,42,44,45]$} \\
\hline $\mathrm{J}$ & 39.2 & Hed & Ara- & 789 & 767 & 605 & 473 & & & {$[7,46]$} \\
\hline $\mathrm{K}$ & 42.3 & OA & GlcA- & $817 / 839$ & 795 & 633 & 457 & & & {$[7,44-46]$} \\
\hline L & 43.2 & OA & $\mathrm{Glc}\left(1^{\prime \prime \prime} \rightarrow 2^{\prime \prime}\right) \mathrm{Glc}\left(1^{\prime \prime} \rightarrow 3^{\prime}\right)$ Ara- & 1097 & 1075 & 913 & 751 & 589 & 457 & {$[45,46]$} \\
\hline $\mathrm{M}$ & 44.1 & OA & Glc $\left(1^{\prime \prime} \rightarrow 3^{\prime}\right)$ Ara- & 935 & 913 & 751 & 589 & 457 & & {$[43,44]$} \\
\hline $\mathrm{N}$ & n.a. & PA & $\mathrm{Glc}\left(1^{\prime \prime} \rightarrow 3^{\prime}\right) \mathrm{Gal}-$ & 1025 & 1003 & 841 & 679 & 517 & & {$[45,46]$} \\
\hline $\mathrm{O}$ & n.a. & PA & $\mathrm{Glc}\left(1^{\prime \prime \prime} \rightarrow 2^{\prime \prime}\right) \mathrm{Glc}\left(1^{\prime \prime} \rightarrow 3^{\prime}\right)$ Ara- & 1157 & 1135 & 973 & 811 & 649 & 517 & {$[43,45,46]$} \\
\hline $\mathrm{P}$ & n.a. & PA & Glc $\left(1^{\prime \prime \prime} \rightarrow 3^{\prime \prime}\right) \mathrm{Xyl}\left(1^{\prime \prime} \rightarrow 2^{\prime}\right) \mathrm{Glc}-$ & 1157 & 1135 & 973 & 811 & 679 & 517 & [43] \\
\hline $\mathrm{Q}$ & n.a. & Hed & $\mathrm{Glc}\left(1^{\prime \prime} \rightarrow 3^{\prime}\right) \mathrm{Gal}-$ & 981 & 959 & 797 & 635 & 473 & & {$[45,46]$} \\
\hline $\mathrm{R}$ & n.a. & $\mathrm{OA}$ & $\mathrm{Xyl}\left(1^{\prime \prime} \rightarrow 3^{\prime}\right) \mathrm{GlcA}-$ & $949 / 971$ & 927 & 765 & 633 & 457 & & {$[46]$} \\
\hline $\mathrm{S}$ & n.a. & OA & $\operatorname{Ara}\left(1^{\prime \prime} \rightarrow 3^{\prime}\right) \mathrm{GlcA}-$ & $949 / 971$ & 927 & 765 & 633 & 457 & & {$[43,44]$} \\
\hline
\end{tabular}

${ }^{a} t_{R}$ : retention time; n.a. not available due to ambiguous ions with identical oligosaccharide sequence and aglycone.

bPA: phytolaccagenic acid, Hed: hederagenin, SA: serjanic acid, OA: oleanolic acid.

'In all compounds the 28- $O$ linked monosaccharide was glucopyranose.

dI to IV refer to sequential sugar losses.

tion time significantly. Compounds $\mathbf{B}, \mathbf{I}$, and $\mathbf{M}$ coincide in their saccharide composition, branching and sequence but comprise varying aglycones. Due to the different polarity of PA, Hed, and OA, they elute at 22, 33 , and $43 \mathrm{~min}$, respectively, and are well separated in clusters. Within these clusters variations in saccharide composition and sequence cause minor shifts (e.g., $\mathbf{R}$ and $\mathbf{S}, 0.5 \mathrm{~min}$ ).

Detailed fragmentation patterns of the four major compounds bearing different aglycones (Figure 4; B, G, I, K) are discussed by the following. Proposals were validated using quantum chemical calculations. The $[\mathrm{M}$ $+\mathrm{H}^{+}$corresponding to the Compounds B $(\mathrm{m} / \mathrm{z}$ 973), $\mathbf{G}$ $(\mathrm{m} / \mathrm{z} 1119), \mathbf{I}(\mathrm{m} / \mathrm{z} 929)$, and $\mathbf{K}(\mathrm{m} / \mathrm{z} 795)$ were selected as precursor ions for MS/MS. Additional MS/MS spectra were acquired by selecting $[\mathrm{M}+\mathrm{H}-\mathrm{Glc}]^{+}$, which was generated at higher ionization voltages by up-front fragmentation, and these spectra provided a more complex fragmentation pattern. In all of the investigated compounds the loss of the C-28 esterified monosaccharide residue seemed to be favored. The resulting signals at $[\mathrm{M}+\mathrm{H}-162]^{+}$correspond to the neutral loss of a hexose residue (Hex; Figure 4; $m / z$ 811, 957, 767, 633 for B, G, I, K, respectively). Quantum chemical calculations using the Gaussian 03 suite of programs [32] show that the $\gamma$-H-rearrangement [21] followed by bond breaking between the C-28 carboxylic acid and the monosaccharide is energetically more favored $(\Delta \mathrm{E}=2.7 \mathrm{kcal} / \mathrm{mol})$ compared to fragmentation at the C-3 bound saccharide. Furthermore, the carboxyl group is the place of initial ionization and therefore the starting point for fragmentation. Due to relative time consuming reaction pattern calculations, transition-state localization of the $\gamma$-H-rearrangement was not successful. For all compounds MS/MS provided a $\mathrm{Y}$ type product ion series (nomenclature according to [36] that allowed sequencing of the oligosaccharide chain linked to the C-3) (Figure 4). For Compounds B and I losses of a hexose and a pentose residue were detected, which is according to the fact that with Glc-Ara- both of them have the same disaccharide linked to the C-3. Fragmentation of $\mathrm{m} / \mathrm{z} 633$ of Compound $\mathbf{K}$ resulted in $\mathrm{m} / \mathrm{z} 457$ corresponding to the $[\mathrm{M}+\mathrm{H}-176]^{+}$ion, which is consistent with the loss of GlcA. These result were emphasized by the SQMS experiment, which showed a $[\mathrm{M}+\mathrm{Na}]^{+}$at $\mathrm{m} / \mathrm{z}$ 817 and $\mathrm{a}[\mathrm{M}+2 \mathrm{Na}-\mathrm{H}]^{+}$at $\mathrm{m} / z$ 839, indicating the presence of a sugar acid. After the initial loss of a hexose residue the sugar sequence of Compound $\mathrm{G}$ was determined as Hex-Hex-Pent- $(\mathrm{m} / \mathrm{z}$ 957 $\rightarrow 795 \rightarrow 633 \rightarrow 501)$ according to Glc-Glc-Ara- (Table 1). Fragmentation of Compounds B, G, I, and $\mathbf{K}$ produced product ions specific for the aglycones PA $(m / z 517)$, SA $(m / z 501)$, Hed $(m / z 473)$, and OA $(m / z 457)$, respectively. The spectra displayed in Figures 4 and 5 were surprising if one takes into account that aglycone-specific fragmentation as well as ion series representing the oligosaccharide sequence are typical for triple quadrupole instruments [24] and were not observed for ITMS. To determine whether this difference is hardware-specific, we acquired additional $\mathrm{MS}^{2}$ spectra of Compound 19 on the LCQ Duo ITMS. The $[\mathrm{M}+\mathrm{Na}]^{+}$ions generated undergo fragmentation similar to results reported for triterpene and steroid saponins [21,24] but do not show any product ion series specific for aglycones and the 
Table 2. Assignment of novel C. quinoa triterpene saponins

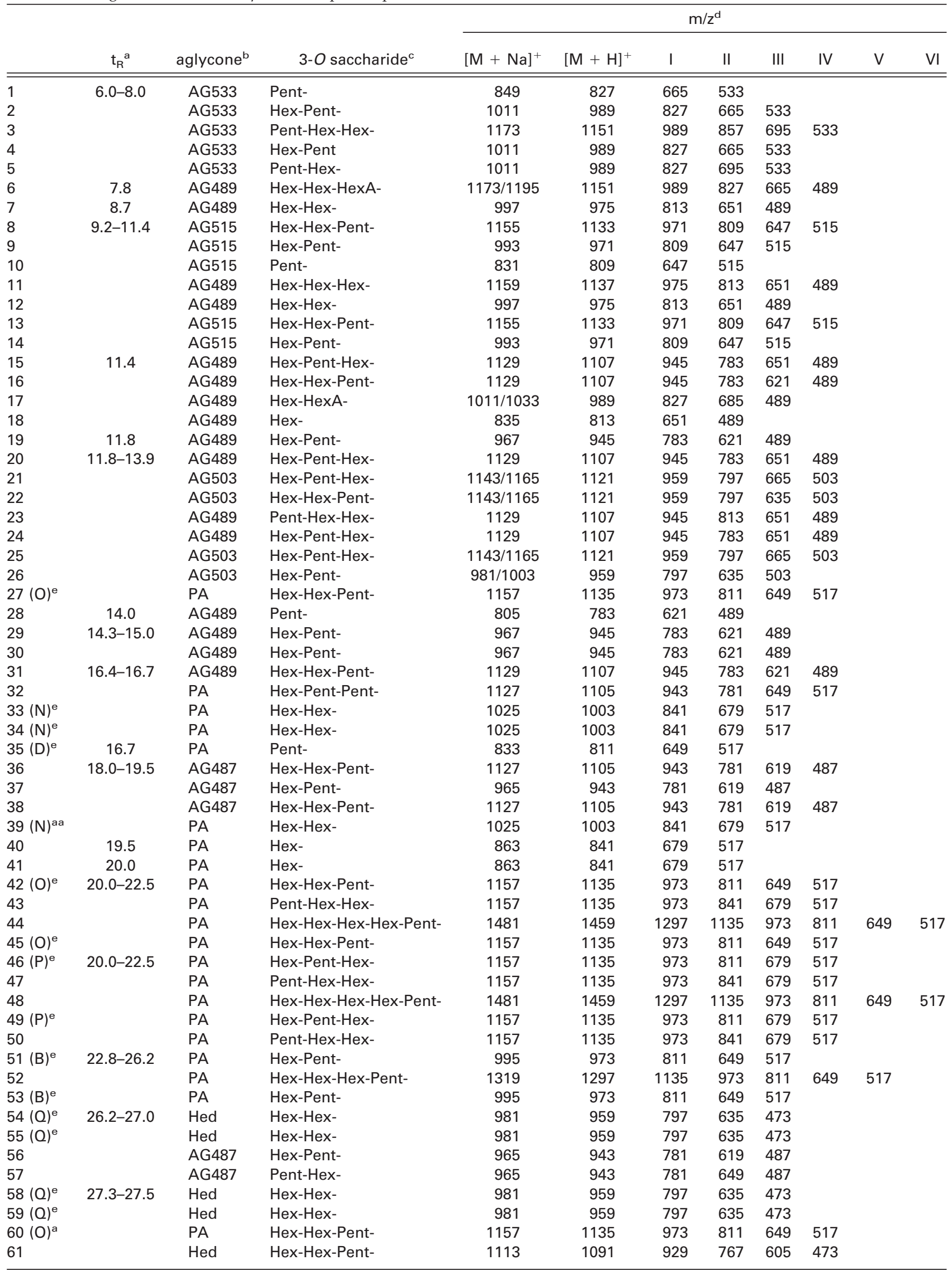


Table 2. (Continued)

\begin{tabular}{|c|c|c|c|c|c|c|c|c|c|c|c|}
\hline & \multirow[b]{2}{*}{$t_{R}{ }^{a}$} & \multirow[b]{2}{*}{ aglycone $^{\text {b }}$} & \multirow[b]{2}{*}{ 3-O saccharide ${ }^{c}$} & \multicolumn{8}{|c|}{$\mathrm{m} / \mathrm{z}^{\mathrm{d}}$} \\
\hline & & & & {$[\mathrm{M}+\mathrm{Na}]^{+}$} & {$[\mathrm{M}+\mathrm{H}]^{+}$} & I & II & III & IV & v & VI \\
\hline 62 & $27.5-28.0$ & Hed & Pent-Hex- & 951 & 929 & 767 & 635 & 473 & & & \\
\hline 63 & & Hed & Pent-Hex-Hex- & 1113 & 1091 & 929 & 797 & 635 & 473 & & \\
\hline 64 & 29.2 & Hed & Hex- & 819 & 797 & 635 & 473 & & & & \\
\hline 65 & $29.9-32.2$ & Hed & Hex-Hex-Pent- & 1113 & 1091 & 929 & 767 & 605 & 473 & & \\
\hline 66 & & Hed & Hex-Pent-Hex- & 1113 & 1091 & 929 & 767 & 635 & 473 & & \\
\hline 67 & & Hed & Pent-Hex-Hex- & 1113 & 1091 & 929 & 797 & 635 & 473 & & \\
\hline $68(I)^{a}$ & 30.2 & Hed & Hex-Pent- & 951 & 929 & 767 & 605 & 473 & & & \\
\hline 69 & 30.6 & Hed & Pent-Hex- & 951 & 929 & 767 & 635 & 473 & & & \\
\hline 70 & 36.4 & OA & Hex-HexA- & $979 / 1001$ & 957 & 795 & 633 & 457 & & & \\
\hline 71 & 37.7 & OA & Hex-Hex- & 965 & 943 & 781 & 619 & 457 & & & \\
\hline 72 & $38.1-39.0$ & Hed & Pent-Pent- & 921 & 899 & 737 & 605 & 473 & & & \\
\hline 73 & & OA & Pent-Hex- & 935 & 913 & 751 & 619 & 457 & & & \\
\hline 74 & & OA & Pent-Hex-Hex- & 1097 & 1075 & 913 & 781 & 619 & 457 & & \\
\hline
\end{tabular}

${ }^{a} t_{R}$ : retention time.

bPA: phytolaccagenic acid, Hed: hederagenin, SA: serjanic acid, OA: oleanolic acid; AG533, AG489, AG515, AG503, AG487 refer to new aglycones with a specific $\mathrm{m} / \mathrm{z}$.

'In all compounds the 28-O linked monosaccharide was a hexose. Hex: hexose, HexA: corresponding sugar acid, Pent: pentose. All monosaccharides were linked linear. The saccharide at the right-end of each sequence is next to the 3-O.

d to VI refer to sequential sugar losses.

eLetters in brackets refer to reported compounds listed in Table 1 which agree with the novel compound in both, the oligosaccharide sequence and the aglycone. As sugar epimers cannot be distinguished by MS an unambiguous assignment was not feasible for these saponins.

oligosaccharide sequence (see Supplementary Material section online). Although the more limited fragmentation obtained may be due to the $[\mathrm{M}+\mathrm{Na}]^{+}$ion being more stable than the $[\mathrm{M}+\mathrm{H}]^{+}$ion, we think this is due to a different waveform design used in the Agilent LC/MSD XCTPlus ITMS to ramp the amplitude of the CID fragmentation voltage. As a consequence, stable product ions or product ions with low-energy fragmentation pathways can also be fragmented. The major fragmentation reactions of the aglycones consist of elimination of water, formic acid, and formaldehyde resulting in an ion series characteristic for each agly-

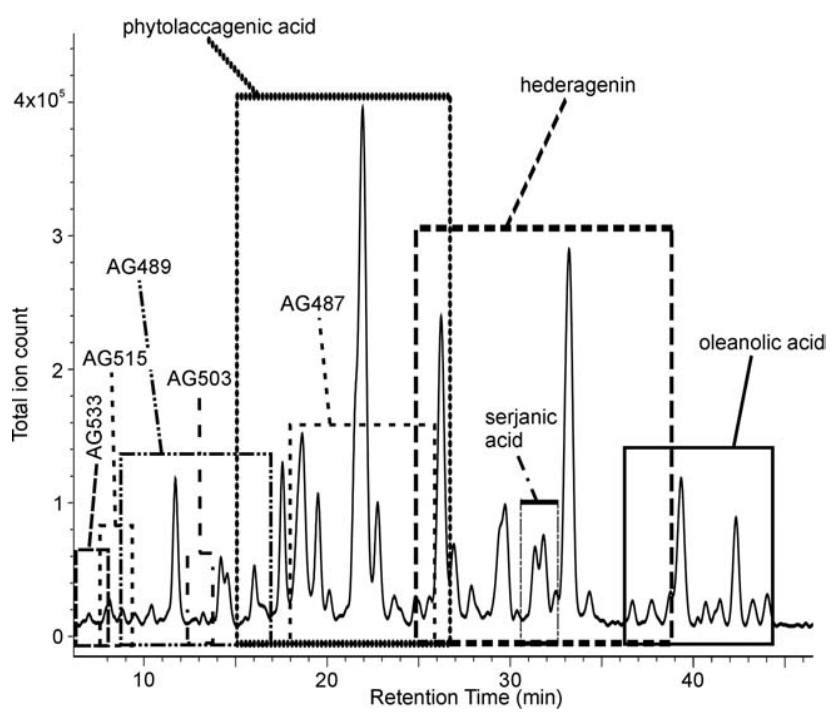

Figure 3. LC/MS chromatogram of $C$. quinoa saponins showing retention time clusters characteristic for saponins comprising a specific aglycone. AG533, AG489, AG515, AG503, AG487 refer to compounds comprising novel aglycones with a specific $\mathrm{m} / \mathrm{z}$. cone (Figure 4). After the loss of all 28-O and 3-O linked saccharides the charge is located at the C-3 hydroxyl group. As a consequence the favored fragmentation step of the aglycone is water elimination and doublebond formation at this specific site resulting in a strong signal at $\left[\mathrm{Agl}+\mathrm{H}-\mathrm{H}_{2} \mathrm{O}\right]^{+}(\mathrm{m} / \mathrm{z} 499,455,439,483$ for PA, Hed, OA, and SA). Quantum chemical calculations gave the lowest elimination energies $(13.5 \mathrm{kcal} / \mathrm{mol})$ between the precursor and the product ion and therefore confirm the experimental results. For PA and Hed where the aglycone comprises an additional hydroxyl group elimination of two water molecules was observed ( $m / z 481$ and 437 , respectively). In contrast to the latter reaction, formation of the double-bond is probably preceded by a 1,3-hydride shift. A higher energy difference between the precursor and the product ion was determined $(13.7 \mathrm{kcal} / \mathrm{mol})$, however the properties of the transition-state cannot be calculated. For all compounds water elimination was accompanied by a neutral loss of formic acid $(46 \mathrm{u})$ incorporating the C-28 carboxylic acid. The double-bond formed as a result has its energetically most favored location between C-17 and C-18 with a $\Delta \mathrm{E}$ of $16.0 \mathrm{kcal} / \mathrm{mol}$ between the precursor and the products. As the energy difference of formic acid elimination is higher than the elimination energy required for water $(\Delta \mathrm{E}=2.5 \mathrm{kcal} / \mathrm{mol})$ the fragmentation pattern and the relative intensities of the detected peaks can be understood clearly. A third neutral loss of formaldehyde $(30 \mathrm{u})$ was of minor intensity and was detected for aglycones comprising a hydroxymethyl residue. Using this information together with fragmentation of the trimethylsilylated hydrolysis products we present proposals for the new aglycones identified here. Even in cases of unknown aglycones, information on the number of hydroxyl and 

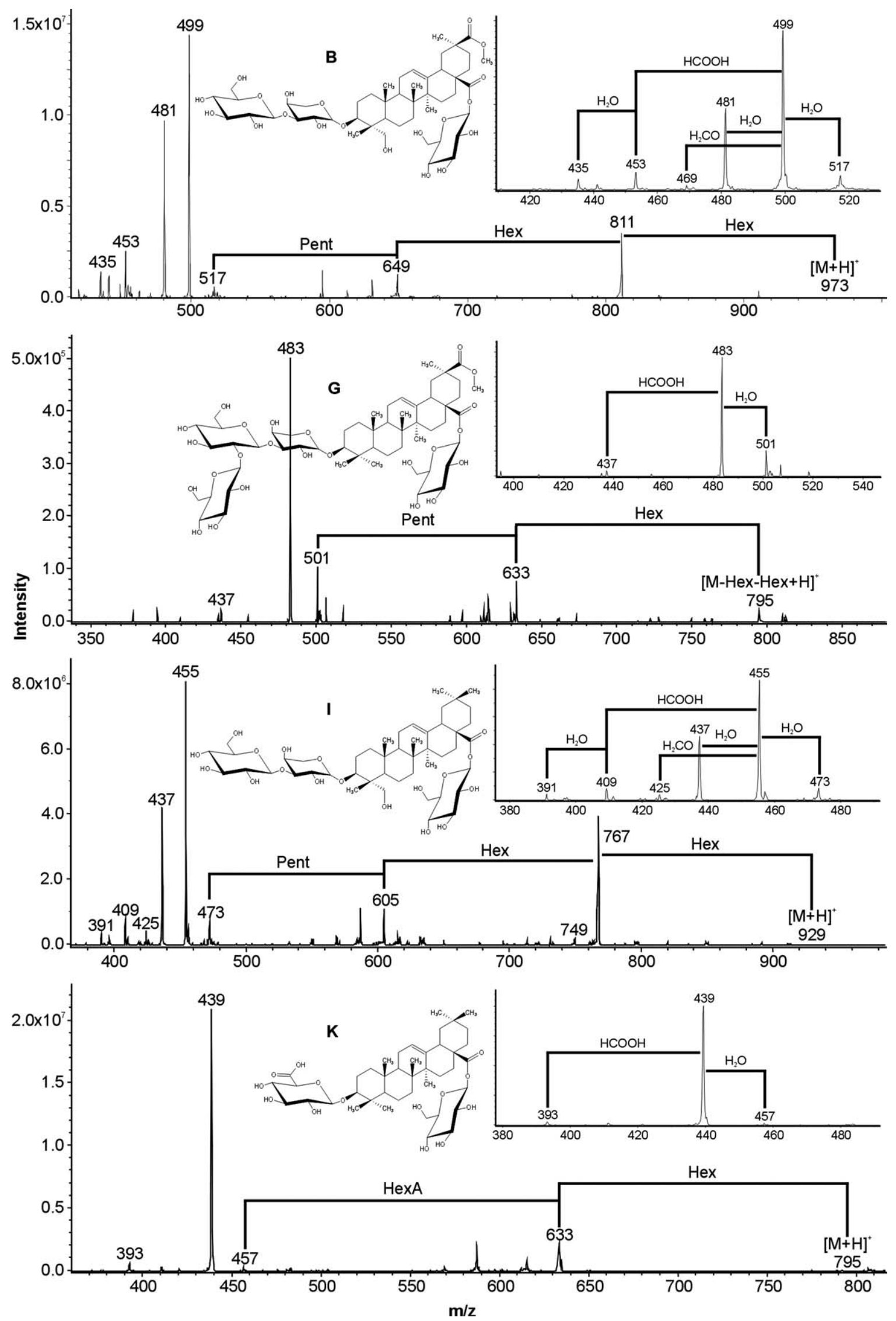

Figure 4. MS/MS spectra on the $[\mathrm{M}+\mathrm{H}]^{+}$of the literature-reported Compounds $\mathbf{B}(\mathrm{m} / \mathrm{z}$ 973), $\mathbf{G}(\mathrm{m} / \mathrm{z}$ 1119), I $(m / z \text { 929), and } \mathbf{K}(m / z ~ 795) \text {. [M }+\mathrm{H}-\mathrm{Hex}]^{+}$was the higher abundant production ion for $\mathbf{B}, \mathbf{I}, \mathbf{K}$, and the $[\mathrm{M}+\mathrm{H}-2 \mathrm{Hex}]^{+}$for $\mathbf{G}$, respectively. Product ion series characteristic for the aglycones phytolaccagenic acid (B), serjanic acid $(\mathbf{G})$, hederagenin $(\mathbf{I})$, and oleanolic acid $(\mathbf{K})$ are displayed in the enlarged spectra. 

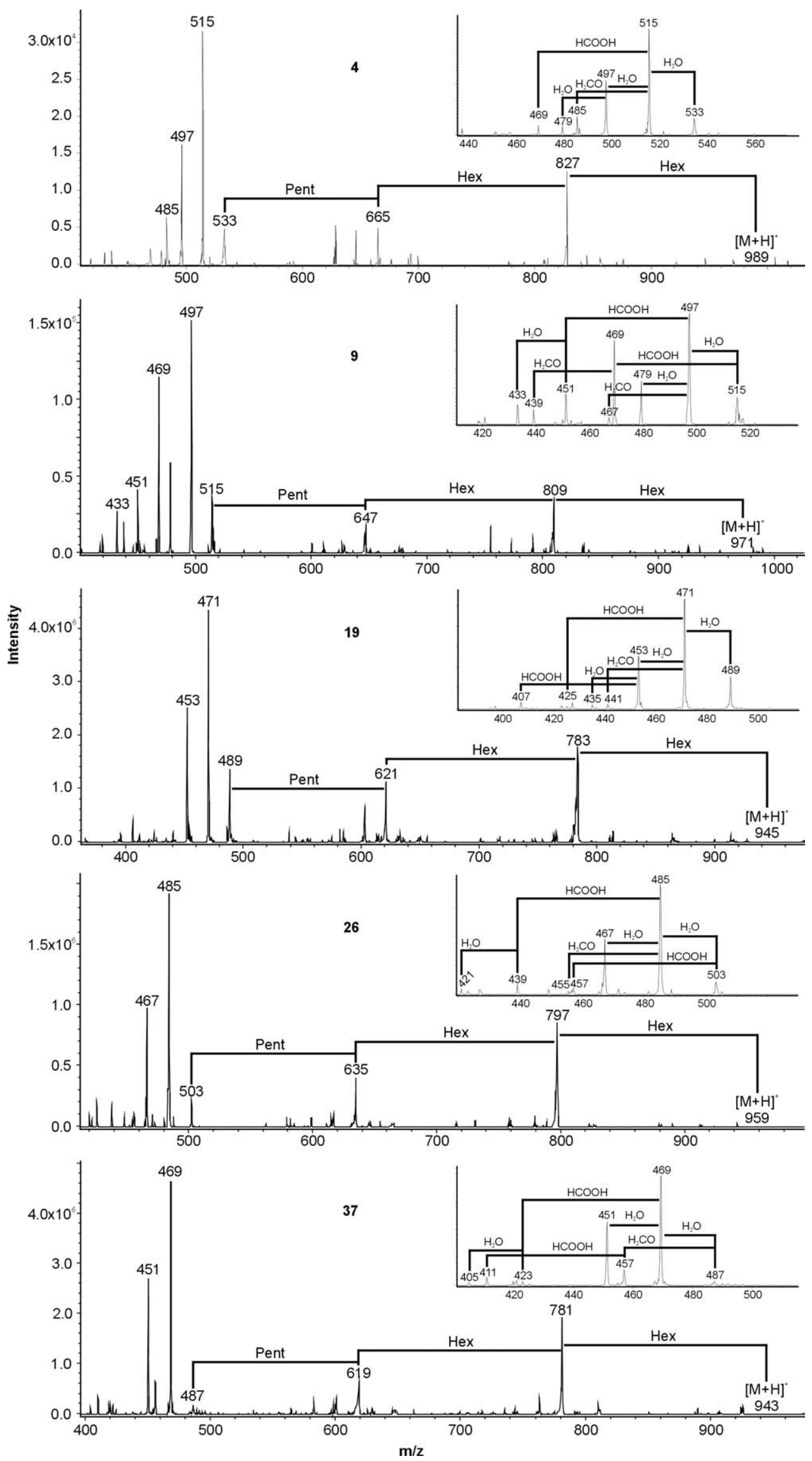

Figure 5. MS/MS spectra on the $[\mathrm{M}+\mathrm{H}]^{+}$of the novel Compounds $4(\mathrm{~m} / \mathrm{z} 989), \mathbf{9}(\mathrm{m} / \mathrm{z} 971), 19(\mathrm{~m} / \mathrm{z}$ 945), $26(\mathrm{~m} / \mathrm{z}$ 959), and $37(\mathrm{~m} / \mathrm{z}$ 943). Product ion series characteristic for the new aglycones AG533 (4), AG515 (9), AG489 (19), AG503 (26), and AG487 (37) are displayed in the enlarged spectra. 
carboxylic acid groups can be obtained. However, stereochemical information as well as the exact structure is not available by MS.

\section{Assignment and Fragmentation of Novel Saponins}

The information obtained from the assignment of $\mathbf{A}$ to $\mathbf{S}$ was used to assign aglycone and saccharide composition of all detected compounds (Table 2). This resulted in around 70 novel saponins comprising five different aglycones which were also clustered in characteristic retention time sections (Figure 3). Fragmentation pathways of the most abundant Compounds 4, 9, 19, 26, and 37 , each representing a group of saponins comprising a novel aglycone, are discussed subsequently. Consistent with the compounds discussed above fragmentation of $[\mathrm{M}+\mathrm{H}]^{+}$at the 28-O-linked hexose was favored. Sequencing of the 3-O-linked sugars displays neutral losses of $162 \mathrm{u}$ and $132 \mathrm{u}$ for all of the compounds (Figure 5) deducing a hexose linked to a pentose. This is not surprising as the most abundant compounds out of each group were taken for discussion, and it was found for PA (B) and Hed (I) that these species are favored. 4 displayed an aglycone-specific product ion at $m / z 533$. Elimination of three water molecules, formic acid, and formaldehyde point to an aglycone similar to PA but bearing an additional hydroxyl group, e.g., at the C-2 [37] or the C-16 [38]. Sugar loss of Compound 9 results in a signal detected at $\mathrm{m} / \mathrm{z} 515$. Fragmentation was similar to 4 except for two instead of three water losses. As, due to the minor abundance, no additional GC/MS information was available for this compound, no proposal is given. $19(\mathrm{~m} / \mathrm{z} 489)$ showed three water losses and fragmentation characteristic for the carboxyl moiety. GC/MS data suggest a 4-fold trimethylsilylated aglycone $(\mathrm{m} / \mathrm{z} 776)$ with 2 -fold derivatization of the retro-Diels-Alder (RDA) product ion $(\mathrm{m} / \mathrm{z}$ 408; see Supplementary Material) [39]. Apart from the C-28 carboxyl group (118 $\mathrm{u}$; HCOOTMS) this suggests an additional hydroxymethyl group at the C-29 or C-30 of that product ion (103 $\mathrm{u}$; TMS, formaldehyde) and at the C-23, C-24, or C-2, respectively [40, 41]. The aglyconespecific product ion of Compound $\mathbf{2 6}$ was detected at $\mathrm{m} / \mathrm{z} 503$ and displayed two water losses in addition to formic acid and formaldehyde. GC/MS suggests a 4-fold trimethylsilylated molecular ion $(\mathrm{m} / \mathrm{z} 790)$ with two derivatization sites at the RDA product ion $(\mathrm{m} / \mathrm{z}$ 422). Two neutral losses of $118 \mathrm{u}$ typical for carboxyl units (HCOOTMS) were detected. This suggests a structure similar to that of $\mathbf{1 9}$ but bearing an additional carboxyl group at the RDA product ion, most probably at the C-29 or C-30. In addition to the $[\mathrm{M}+\mathrm{Na}]^{+}(\mathrm{m} / \mathrm{z}$ 981) LC-SQMS gave an additional $[\mathrm{M}+2 \mathrm{Na}-\mathrm{H}]^{+}$at $\mathrm{m} / \mathrm{z} 1003$ characteristic for a free carboxyl group and therefore emphasizes our proposal. Apart from neutral losses detected for all aglycones $37(\mathrm{~m} / \mathrm{z} 487)$ undergoes only two water elimination steps. GC/MS detected a 3-fold derivatized aglycone $(\mathrm{m} / \mathrm{z}$ 702) with the carboxyl unit being the only trimethylsilylated functional group within the RDA product ion $(\mathrm{m} / \mathrm{z} 334)$. A strong loss of $28 \mathrm{u}$ due to elimination of ethylene from the RDA indicates a terminal ethyl group, probably at the C-29 or C-30. Based upon different polarities, these proposals are according with the elution order of their corresponding saponins within the chromatographic separation.

\section{Isolation and Structure Determination of Compound 19}

To confirm the accuracy of the assignment procedure and due to the identification of new aglycones, the most abundant novel Compound 19 was isolated and characterized by NMR (see Supplementary Material for ${ }^{1} \mathrm{H}$ and ${ }^{13} \mathrm{C}$ resonances). Using ${ }^{1} \mathrm{H} /{ }^{13} \mathrm{C}$ chemical shifts and absolute values of the vicinal coupling constants the configuration at the anomeric protons for arabinopyranose and glucopyranose were determined as $\alpha$ and $\beta$, respectively. NOESY experiments and the coupling constants of vicinal ${ }^{1} \mathrm{H}-{ }^{1} \mathrm{H}$ correlations were used to determine the relative stereochemistry. The novel Compound 19 was assigned as bidesmosidic triterpene saponin 3-23-30-trihydroxyolean-12-en-28-oic acid 3-O[ $\beta$-D-glucopyranosyl $\quad\left(1^{\prime \prime} \rightarrow 3^{\prime}\right)-\alpha$-L-arabinopyranosyl]$28-O-\beta$-D-glucopyranoside, which is emphasized by structural information obtained from GC/MS and ESIMS/MS (Figure 5). The $[\mathrm{M}+\mathrm{H}-162]^{+}$at $\mathrm{m} / \mathrm{z} 783$ corresponds to the neutral loss of the 28-O-linked glucopyranose. The ion series sequencing the 3-Olinked moiety displayed losses of $162 \mathrm{u}$ and $132 \mathrm{u}$ representing the Glc $\left(1^{\prime \prime} \rightarrow 3^{\prime}\right)$-Ara-disaccharide. The three neutral losses of water as well as of formic acid arise from the three hydroxyl groups at C-3, C-23, C-30, and the C-28 carboxyl moiety, respectively. The molecular ion of the trimethylsilylated aglycone $(\mathrm{m} / \mathrm{z} 776)$ agrees with a 4 -fold trimethylsilylation and rearranges to the product ion at $\mathrm{m} / \mathrm{z} 408$ (see Supplementary Material). Two neutral losses of $103 \mathrm{u}$ (TMS, formaldehyde) and $118 \mathrm{u}$ (HCOOTMS) are due to TMS groups derivatizing the C-30 hydroxyl and C-28 carboxylic acid, respectively. Our results show that although stereochemical information on the compounds is not available by MS structural information can be extracted from the spectra and proposals can be given.

\section{Conclusions}

The combination of two different mass spectrometric techniques (GC/MS and nLC-MS/MS) was proven to be a powerful tool for the assignment of reported as well as the identification and assignment of a great number of novel Chenopodium quinoa triterpene saponins. LC-MS/MS allowed a complete preassignment and identification of the major constituents and aglycones, respectively. Structural information on the nine different aglycones (nature, substitution) and the saccharide moieties (sequence, composition, and branch- 
ing) can be extracted from the MS spectra. However, stereochemistry and the exact structure cannot be deduced from the mass spectra. Proposals for novel saponin structures can be given as demonstrated for about 70 compounds and verified by NMR spectroscopy. Fragmentation pathway analysis using quantum chemical density functional calculations is currently not established but assists in interpretation of mass spectra and will be an effective tool even for transition-state localization in the future. As this methodology allows calculation of elimination and bond-breaking energies, proposals and possibilities for different fragmentation reactions can be given and agree with the experimental results. Compared to the commonly performed and relative time consuming isolation and structure determination procedure using successive column chromatography and NMR, the MS-based assignment can be obtained in a few hours and is recommended for directed isolation and structure determination routines. Our rapid and complete approach is particularly suitable for quality control and screening of $C$. quinoa extracts designated for pharmaceutical, agricultural, and industrial applications.

\section{Acknowledgments}

The authors gratefully acknowledge the referees for their helpful comments, and Agilent Technologies for providing the 1100 Series nanoflow LC system and the LC/MSD XCTPlus ITMS. In the latter regard, the authors especially acknowledge Friedrich Mandl, Hermann Rausch, Helmut Eckhardt and Volker Haeupl for their kind support. TM thanks Walter Fabian for guidance and fruitful discussions regarding the quantum chemical computations.

\section{References}

1. Rechinger, K. H. Phytolaccacae, Amaranthaceae, Chenopodiaceae, Illebraceae, Carophyllaceae, Portulacaceae. In llustrierte Flora von Mitteleuropa, Vol. III; Hegi, G.; Conert, H. J., Eds.; Parey: Berlin/Hamburg, 1979, pp 478

2. Mahoney, A. W.; Lopez, J. G.; Hendricks, D. G. Evaluation of the protein quality of quinoa. J. Agric. Food Chem. 1975, 23, 190-193.

3. Prakash, D.; Pal, M. Chenopodium: Seed protein, fractionation, and amino acid composition. Int. J. Food Sci. Nutr. 1998, 49, 271-275.

4. Dutcheshen, J. M. Plant protection against bacterial diseases using saponins. U.S. Patent no. 2003162731; 2003

5. Estrada, A.; Li, B.; Laarveld, B. Adjuvant action of Chenopodium quinoa saponins on the induction of antibody responses to intragastric and intranasal administered antigens in mice. Comp. Immunol. Microb. 1998, 21, 225-236.

6. Meyer, B. N.; Heinstein, P. F.; Burnouf-Radosevich, M.; Delfel, N. E.; McLaughlin, J. L. Bioactivity-directed isolation and characterization of quinoside A: One of the toxic/bitter principles of quinoa seeds (Chenopodium quinoa Willd). J. Agric. Food Chem. 1990, 38, 205-208.

7. Woldemichael, G. M.; Wink, M. Identification and biological activities of triterpenoid saponins from Chenopodium quinoa. J. Agric. Food Chem. 2001, 49, 2327-2332.

8. Estrada, A., Redmond, M. J., Laarveld, B. Quinoa saponin compositions and methods of use. U.S. Patent no. 15597807; 1997.

9. Ruiz, W. A.; Farfan, J. A.Determination of oleanolic acid in quinoa by gas-liquid chromatography (Chenopodium quinoa, Willd cv Kcancolla) Bol. Soc. Quim. Peru 1979, 45, 266-276.

10. Burnouf-Radosevich, M.; Delfel, N. E.; England, R. Gas chromatography-mass spectrometry of oleanane- and ursane-type triterpenesapplication to Chenopodium quinoa triterpenes. Phytochemistry 1985, 24, 2063-2066.

11. Cuadrado, C.; Ayet, G.; Burbano, C.; Muzquiz, M.; Camacho, L.; Cavieres, E.; Lovon, M.; Osagie, A.; Price, K. R. Occurrence of saponins and sapogenols in Andean crops. J. Sci. Food Agric. 1995, 67, 169-172.
12. Mastebroek, H. D.; Limburg, H.; Gilles, T.; Marvin, H. J. P. Occurrence of sapogenins in leaves and seeds of quinoa (Chenopodium quinoa Willd). J. Sci. Food Agric. 2000, 80, 152-156.

13. Muir, A. D.; Ballantyne, K. D.; Hall, T. W. LC-MS and LC-MS/MS analysis of saponins and sapogenins-comparison of ionization techniques and their usefulness in compound identification. Proceedings of the Phytochemical Society of Europe, Vol. XLV; Oleszek W.; Marston, A., Eds; Springer: Berlin, 2000, pp 35-41.

14. Ridout, C. L.; Price, K. R.; DuPont, M. S.; Parker, M. L.; Fenwick, G. R. Quinoa saponins-analysis and preliminary investigations into the effects of reduction by processing. I. Sci. Food Agric. 1991, 54, 165-176.

15. Ruiz, W. A.; Farfan, J. A. Evaluation of four gas chromatography methods for determining oleanolic acid in quinoa (Chenopodium quinoa Willd, var. Kcancolla). Bol. Soc. Quim. Peru 1980, 46, 76-84.

16. Woldemichael, G. M. Phytochemical investigation of four triterpene, saponin, and alkaloid containing plants; Ph.D. Thesis, University of Heidelberg, 2000, pp 1-188.

17. Li, B.; Abliz, Z.; Tang, M. J.; Fu, G. M.; Yu, S. S. Rapid structural characterization of triterpenoid saponins in crude extract from Symplocos chinensis using liquid chromatography combined with electrospray ionization tandem mass spectrometry. J. Chromatogr. A 2006, 1101, 53-62.

18. Guo, M.; Song, F.; Bai, Y.; Liu, Z.; Liu, S. Rapid analysis of a triterpenoid saponin mixture from plant extracts by electrospray ionization multistage tandem mass spectrometry (ESI-MS). Anal. Sci. 2002, 18, 481-484.

19. Fang, S. P.; Hao, C. Y.; Liu, Z. Q.; Song, F. R.; Liu, S. Y. Application of electrospray ionization mass spectrometry combined with sequential tandem mass spectrometry techniques for the profiling of steroidal saponin mixture extracted from Tribulus terrestris. Planta Med. 1999, 65, 68-73.

20. Van Setten, D. C.; Zomer, G.; Van de Werken, G.; Wiertz, E. J. H. J.; Leeflang, B. R.; Kamerling, J. P. Ion trap multiple-stage tandem mass spectrometry as a pre-NMR tool in the structure elucidation of saponins. Phytochem. Anal. 2000, 11, 190-198.

21. Van Setten, D. C.; Ten Hove, G. J.; Wiertz, E. J. H. J.; Kamerling, J. P.; Van de Werken, G. Multiple-stage tandem mass spectrometry for structural characterization of saponins. Anal. Chem. 1998, 70, 4401-4409.

22. Broberg, S.; Nord, L. I.; Kenne, L. Oligosaccharide sequences in Quillaja saponins by electrospray ionization ion trap multiple-stage mass spectrometry. J. Mass Spectrom. 2004, 39, 691-701.

23. Huhman, D. V.; Sumner, L. W. Metabolic profiling of saponins in Medicago sativa and Medicago truncatula using HPLC coupled to an electrospray ion-trap mass spectrometer. Phytochemistry 2002, 59, 347360.

24. Dal Piaz, F.; De Leo, M.; Braca, A.; De Simone, F.; Morelli, I.; De Tommasi, N. Electrospray ionization mass spectrometry for identification and structural characterization of pregnane glycosides. Rapid Commun. Mass Spectrom. 2005, 19, 1041-1052.

25. Cui, M.; Song, F.; Zhou, Y.; Liu, Z.; Liu, S. Rapid identification of saponins in plant extracts by electrospray ionization multi-stage tandem mass spectrometry and liquid chromatography/tandem mass spectrometry. Rapid Commun. Mass Spectrom. 2000, 14, 1280-1286.

26. Song, F. R.; Cui, M.; Liu, Z. Q.; Yu, B.; Liu, S. Y. Multiple-stage tandem mass spectrometry for differentiation of isomeric saponins. Rapid Commun. Mass Spectrom. 2004, 18, 2241-2248.

27. Liu, S. Y.; Cui, M.; Liu, Z. Q.; Song, F. R.; Mo, W. J. Structural analysis of saponins from medicinal herbs using electrospray ionization tandem mass spectrometry. I. Am. Soc. Mass Spectrom. 2004, 15, 133-141.

28. Wang, X. M.; Sakuma, T.; Asafu-Adjaye, E.; Shiu, G. K. Determination of ginsenosides in plant extracts fromPanax ginseng and Panax quinquefolius L. by LC/MS/MS. Anal. Chem. 1999, 71, 1579-1584.

29. Liu, Y.; Liang, F.; Cui, L.; Xia, M. Zhao, L.; Yang, Y.; Shi, I.; Abliz, Z. Multi-stage mass spectrometry of furostanol saponins combined with electrospray ionization in positive and negative ion modes. furostanol Rapid Commun. Mass Spectrom. 2004, 18, 235-238.

30. Song, F. R. Liu, Z. Q.; Liu, S. Y. Cai, Z. W.Differentiation and identification of ginsenoside isomers by electrospray ionization tandem mass spectrometry. Anal. Chim. Acta. 2005, 77, 531-692.

31. Hypercube, I 2002. HyperChem Professional 7.1, Gainesville, FL.

32. Frisch, M. J.; G. W. T.; Schlegel, H. B.; Scuseria, G. E.; Robb, M. A.; Cheeseman, J. R.; Montgomery, J. A., Jr.; Vreven, T.; Kudin, K. N.; Burant, J. C.; Millam, J. M.; Iyengar, S. S.; Tomasi, J.; Barone, V.; Mennucci, B.; Cossi, M.; Scalmani, G.; Rega, N.; Petersson, G. A.; Nakatsuji, H.; Hada, M.; Ehara, M.; Toyota, K.; Fukuda, R.; Hasegawa, J.; Ishida, M.; Nakajima, T.; Honda, Y.; Kitao, O.; Nakai, H.; Klene, M.; Li, X.; Knox, J. E.; Hratchian, H. P.; Cross, J. B.; Bakken, V.; Adamo, C.; Jaramillo, J.; Gomperts, R.; Stratmann, R. E.; Yazyev, O.; Austin, A. J.; Cammi, R.; Pomelli, C.; Ochterski, J. W.; Ayala, P. Y.; Morokuma, K. Voth, G. A.; Salvador, P.; Dannenberg, J. J.; Zakrzewski, V. G.; Dapprich, S.; Daniels, A. D.; Strain, M. C.; Farkas, O.; Malick, D. K.; Rabuck, A. D.; Raghavachari, K.; Foresman, J. B.; Ortiz, J. V.; Cui, Q.; Baboul, A. G.; Clifford, S.; Cioslowski, J.; Stefanov, B. B.; Liu, G.; Liashenko, A.; Piskorz, P.; Komaromi, I.; Martin, R. L.; Fox, D. J.; Keith, T.; Al-Laham, M. A.; Peng, C. Y.; Nanayakkara, A.; Challacombe, M.; Gill, P. M. W.; Johnson, B.; Chen, W.; Wong, M. W.; Gonzalez, C.; Pople, J. A. Gaussian 2004; Gaussian, Inc.: Wallingford, CT.

33. Becke, A. D. Density-functional thermochemistry. 3. The role of exact exchange. J. Chem. Phys. 1993, 98, 5648-5652. 
34. Lee, C. T.; Yang, W. T.; Parr, R. G. Development of the Collesalvetti correlation-energy formula into a functional of the electron-density. Phys. Rev. B 1988, 37, 785-789.

35. Oleszek, W. A. Chromatographic determination of plant saponins. J. Chromatogr. A 2002, 967, 147-162.

36. Domon, B.; Costello, C. E. A Systematic nomenclature for carbohydrate fragmentations in FAB-MS/MS spectra of glycoconjugates. Glycoconj. J 1988, 5, 397-409.

37. Takahashi, H.; Namikawa, Y.; Tanaka, M.; Fukuyama, Y. Triterpene glycosides from the cultures of Phytolacca americana. Chem. Pharm. Bull. 2001, 49, 246-248.

38. Kite, G. C.; Howes, M.-J. R.; Simmonds, M. S. J. Metabolomic analysis of saponins in crude extracts of Quillaja saponaria by liquid chromatography/mass spectrometry for product authentication. Rapid Commun. Mass Spectrom. 2004, 18, 2859-2870.

39. Hostettmann, K.; Marston, A. Saponins; Cambridge University Press: Cambridge, 1995, pp 1-560.
40. Calis, I.; Kirmizibekmez, H.; Tasdemir, D.; Rueedi, P. Two new triterpene and a new nortriterpene glycosides from Phlomis viscosa. Helv. Chim. Acta 2004, 87, 611-619.

41. Braca, A.; Bader, A.; Siciliano, T.; Morelli, I.; De Tommasi, N. New pyrrolizidine alkaloids and glycosides from Anchusa strigosa. Planta Med. 2003, 69, 835-841.

42. Dini, I.; Tenore, G. C.; Schettino, O.; Dini, A. New oleanane saponins in Chenopodium quinoa. J. Agric. Food Chem. 2001, 49, 3976-3981.

43. Dini, I.; Schettino, O.; Simioli, T.; Dini, A. Studies on the constituents of Chenopodium quinoa seeds: Isolation and characterization of new triterpene saponins. J. Agric. Food Chem. 2001, 49, 741-746.

44. Dini, I.; Carlo Tenore, G.; Dini, A. Oleanane saponins in "kancolla", a sweet variety of Chenopodium quinoa. J. Nat. Prod. 2002, 65, 1023-1026.

45. Zhu, N.; Sheng, S.; Sang, S.; Jhoo, J.-W.; Bai, N.; Karwe, M. V.; Rosen, R. T.; Ho, C.-T. Triterpene Saponins from debittered quinoa (Chenopodium quinoa) seeds. J. Agric. Food Chem. 2002, 50, 865-867.

46. Mizui, F.; Kasai, R.; Ohtani, K.; Tanaka, O. Saponins from bran of quinoa, Chenopodium quinoa Willd. II. Chem. Pharm. Bull. 1990, 38, 375-377. 